\title{
The effects of systemic oxygenation on cerebral oxygen saturation and its relationship to mixed venous oxygen saturation: A prospective observational study comparison of the INVOS and ForeSight Elite cerebral oximeters
}

\section{Effets de l'oxygénation systémique sur la saturation cérébrale en oxygène et ses rapports avec la saturation veineuse mixte en oxygène : étude observationnelle prospective comparant les oxymètres cérébraux INVOS et ForeSight Elite}

\author{
Christian Schmidt • Matthias Heringlake, MD • Patrick Kellner, MD • \\ Astrid Ellen Berggreen, MD · Holger Maurer, MD - Sebastian Brandt, MD • \\ Bence Bucsky, MD $\cdot$ Michael Petersen, MD $\cdot$ Efstratios I. Charitos, MD, PhD \\ Received: 12 October 2017/Revised: 28 January 2018/Accepted: 29 January 2018/Published online: 26 February 2018 \\ (C) Canadian Anesthesiologists' Society 2018
}

\begin{abstract}
Purpose The present study aimed to test the hypothesis that cerebral oxygen saturation $\left(\mathrm{ScO}_{2}\right)$ measurements with the INVOS-5100-C and the ForeSight-Elite cerebral oximeters vary in their correlation with mixed venous oxygen saturation $\left(\mathrm{SvO}_{2}\right)$ upon changes in systemic oxygenation in extubated cardiac surgical patients. Additionally, we aimed to elucidate whether the $\mathrm{ScO}_{2}$
\end{abstract}

These data were presented in abstract form at the Annual Meeting of the Society of Cardiovascular Anesthesiology, 2017, in Orlando, FL, USA, and during the Annual German Anaesthesia Congress, 2017, in Nürnberg, Germany.

Electronic supplementary material The online version of this article (https://doi.org/10.1007/s12630-018-1093-3) contains supplementary material, which is available to authorized users.

C. Schmidt · M. Heringlake, MD $(\bowtie) \cdot$ P. Kellner, MD .

A. E. Berggreen, MD · H. Maurer, MD - S. Brandt, MD Department of Anesthesiology and Intensive Care Medicine, University of Lübeck, Ratzeburger Allee 160, 23538 Lübeck, Germany

e-mail: Heringlake@t-online.de

B. Bucsky, MD · M. Petersen, MD

Department of Cardiac and Thoracic Vascular Surgery,

University of Lübeck, Lübeck, Germany

E. I. Charitos, $\mathrm{MD}, \mathrm{PhD}$

Department of Cardiac Surgery, Martin Luther University, Halle, Germany measurements of both devices can be used interchangeably to detect reduced $\mathrm{SvO}_{2}$.

Methods Forty-eight spontaneously breathing patients extubated after cardiac surgery were included in this prospective observational study. The patients were exposed to both high (10 oxygen $\mathrm{L} \cdot \mathrm{min}^{-1}$ via face mask) and low (room air) inspiratory oxygen concentrations. Bihemispherical $\mathrm{ScO}_{2}$ was determined with the INVOS and ForeSight Elite cerebral oximeters. The $\mathrm{SvO}_{2}$ was measured with a pulmonary artery catheter.

Results Significant changes in oxygen delivery, $\mathrm{ScO}_{2}$ (by both cerebral oximeters), and $\mathrm{SvO}_{2}$ were observed upon variation of oxygenation. The minimum mean (standard deviation) $\mathrm{ScO}_{2}\left(\mathrm{ScO}_{2 m i n}\right)$ using the INVOS and ForeSight did not differ significantly during high oxygen delivery [63.1 (8.6) \% vs 65.8 (4.7) \%, respectively; $P=0.07$ ], but during low oxygen delivery, the INVOS value was significantly lower than that of the ForeSight oximeter [56.7 (8.9) \% vs 61.3 (4.4) \%, respectively; $P=0.003$ ]. Both devices differed in the correlation between $\mathrm{ScO}_{2 m i n}$ and $\mathrm{SvO}_{2}$ for the combined oxygenation data (0.59, INVOS vs 0.28, ForeSight; correlation difference, 0.31; Bonferroni-adjusted $95 \%$ confidence interval [CI], 0.08 to $0.54 ; P=0.008)$. The receiver-operating curve analysis revealed an area under the curve of 0.83 (95\% CI, 0.74 to 0.9; $\mathrm{P}=0.005)$ for detecting an $\mathrm{SvO}_{2}$ below $50 \%$ by $\mathrm{ScO}_{2 \text { min }}$ with the INVOS and 0.51 (95\% CI, 0.41 to $0.62 ; \mathrm{P}$ = 0.92), respectively, with the ForeSight. 
Conclusions These findings suggest that the cerebral oximeters tested react differently to variations in systemic oxygenation and in their relationship with $\mathrm{SvO}_{2}$ and thus give different information on cardiopulmonary function. These findings raise doubt about whether these devices should be used interchangeably.

\section{Résumé}

Objectif Cette étude a voulu tester l'hypothèse selon laquelle les mesures de la saturation cérébrale en oxygène $\left(\mathrm{ScO}_{2}\right)$ avec les oxymètres cérébraux INVOS-5100-C et ForeSight-Elite varient dans leur corrélation avec la saturation veineuse mixte en oxygène $\left(\mathrm{SvO}_{2}\right)$ au moment de changements d'oxygénation systémique chez des patients chirurgicaux cardiaques extubés. De plus, nous avons voulu élucider la question de savoir si les mesures de $\mathrm{ScO}_{2}$ effectuées par les deux dispositifs pouvaient être utilisées indifféremment pour détecteur une réduction de la $\mathrm{SvO}$.

Méthodes Quarante-huit patients extubés respirant spontanément après une chirurgie cardiaque ont été inclus dans cette étude observationnelle prospective. Les patients ont été exposés à des concentrations inspiratoires en oxygène élevées $\left(10 \mathrm{~L} \cdot \mathrm{min}^{-1}\right.$ d'oxygène par masque facial) et basses (air ambiant). $\mathrm{La} \mathrm{ScO}_{2}$ bi-hémisphérique a été déterminée au moyen des oxymètres cérébraux INVOS et ForeSight Elite. $\mathrm{La} \mathrm{SvO}_{2}$ a été mesurée via un cathéter de l'artère pulmonaire.

Résultats Des changements significatifs de l'apport d'oxygène, de la $\mathrm{ScO}_{2}$ (selon les deux oxymètres cérébraux) et de la $\mathrm{SvO}_{2}$ ont été observés au moment du changement d'oxygénation. Les $\mathrm{ScO}_{2}$ moyennes minimums (écart-type) ( $\left.\mathrm{ScO}_{2 m i n}\right)$ obtenues avec INVOS et ForeSight n'étaient pas significativement différente au cours de l'administration d'oxygène à forte concentration (respectivement, 63,1 [8,6] \% contre 65,8 [4,7]\%; $P=$ $0,07)$ tandis que pendant l'administration d'oxygène à faible concentration, la valeur indiquée par l'INVOS était significativement inférieure à celle de l'oxymètre ForeSight (respectivement, 56,7 [8,9] \% contre 61,3 [4,4]\%; $P<0,003)$. Les deux dispositifs présentaient une corrélation différente entre la $\mathrm{ScO}_{2 \min }$ et la $\mathrm{SvO} \mathrm{O}_{2}$ pour les données d'oxygénation combinées (INVOS $=0,59$ contre ForeSight $=0,28$; différence de corrélation, 0,31; intervalle de confiance [IC] à $95 \%$ [avec correction de Bonferroni] : 0,08 à 0,54; $P<0,008)$. L'analyse de la courbe d'efficacité du récepteur (ROC) a révélé une aire sous la courbe de 0,83 (IC à $95 \%$ : 0,74 à 0,9; $P=0,005$ ) pour la détection d'une $\mathrm{SvO}_{2}$ inférieure de $50 \%$ par $\mathrm{ScO}_{2 \min }$ avec l'INVOS et de 0,51 (IC à $95 \%$ :0,41 à 0,62; $P=0,92)$ avec le ForeSight.

Conclusions Ces constatations suggèrent que les oxymètres cérébraux testés réagissent différemment aux variations d'oxygénation systémique et dans leurs rapports avec la $\mathrm{SvO}_{2}$; ils donnent donc des informations différentes sur la fonction cardiopulmonaire. Ces constatations remettent donc en question l'utilisation équivalente de ces dispositifs.

Cerebral oxygen saturation $\left(\mathrm{ScO}_{2}\right)$ monitoring by nearinfrared reflectance spectroscopy (NIRS) is increasingly used perioperatively for the indirect assessment of the cerebral blood flow and cerebral oxygen balance (i.e., the ratio between cerebral oxygen delivery and demand). ${ }^{1,2}$

A growing number of single-centre studies in various clinical fields support an association between perioperative decreases in $\mathrm{ScO}_{2}$ and increased postoperative neurologic and/or general morbidity. ${ }^{3-5}$ In addition, several studies have shown that avoiding cerebral desaturation can lead to improved outcomes. ${ }^{6-8}$ Nevertheless, there is also some controversy over whether $\mathrm{ScO}_{2}$ is indeed superior to somatic tissue oxygen saturation in the ability to predict adverse outcomes. ${ }^{9}$

Previous studies have shown that the $\mathrm{ScO}_{2}$ signal derived from various cerebral oximeters is influenced by variations in systemic hemodynamics and may thus also reflect the systemic oxygen balance and oxygen delivery. ${ }^{10-12}$ In support of this assumption, our group has previously shown correlations between $\mathrm{ScO}_{2}$ (measured with the INVOS 5100-C [Medtronic; Boulder, $\mathrm{CO}$, USA] $)$ and mixed venous oxygen saturation $\left(\mathrm{SvO}_{2}\right)$ considered the gold standard for monitoring the systemic ratio between oxygen delivery and demand-in patients undergoing transapical aortic valve implantation ${ }^{10}$ and in extubated patients after cardiac surgery. ${ }^{11}$ Moerman et al. made comparable observations in patients undergoing offpump coronary artery bypass grafting procedures employing not only the INVOS, but also the Foresight Elite monitor (CAS Medical Systems; Branford, CN, USA). ${ }^{12}$

In further support of an influence of the systemic circulation on the NIRS-derived $\mathrm{ScO}_{2}$, Meng and colleagues have shown that changes in cardiac output induced by infusion of either phenylephrine or ephedrine were associated with concomitant changes in $\mathrm{ScO}_{2}$ determined with the Oxiplex TS cerebral oximeter (ISS, Inc.; Champaign, IL, USA). ${ }^{13}$ Consistent with these findings, inverse correlations between INVOS-derived $\mathrm{ScO}_{2}$ and the plasma concentration of cardiovascular risk markers such as high-sensitive troponin and N-terminal pro-B-type natriuretic peptide have also been observed. ${ }^{14}$ Considering that preoperative $\mathrm{ScO}_{2}$ levels may be used for risk stratification in patients undergoing cardiac surgery, ${ }^{14}$ 
it has been suggested that NIRS-derived $\mathrm{ScO}_{2}$ may not only be used as a neurologic monitoring tool but also for assessing the systemic circulation. ${ }^{2}$

An increasing number of cerebral oximeters from different manufacturers are commercially available. Despite having the basic concepts of NIRS-derived $\mathrm{ScO}_{2}$ in common, these devices vary considerably in both the number and wavelengths of light employed as well the algorithms used to derive $\mathrm{ScO}_{2} \cdot{ }^{15}$ Notably, they also differ regarding the relative influence of extracranial tissue perfusion. ${ }^{16,17}$ Consequently, absolute baseline $\mathrm{ScO}_{2}$ and the relative changes upon desaturation differ markedly between devices from various manufacturers. ${ }^{18}$ Very limited data are available addressing the possible implications of these differences.

Interestingly, most of the data showing that perioperative decreases in $\mathrm{ScO}_{2}$ may be associated with increased morbidity, that maintaining cerebral oxygenation may also lead to reduced complications, and that cerebral oxygenation reflects systemic cardiopulmonary performance ${ }^{1-5,10-12,14,19}$ have been specifically gathered with the INVOS device. It is presently unclear whether results derived from this specific device may be directly transferred to other cerebral oximeters. For example, recent work has shown that the INVOS 5100-C and Foresight
Elite monitors react differently to acute changes in arterial blood pressure. ${ }^{12}$

The primary aim of the present study was to test the hypothesis that $\mathrm{ScO}_{2}$ measurements with the INVOS-5100$\mathrm{C}$ and the ForeSight-Elite cerebral oximeter vary in their correlation with $\mathrm{SvO}_{2}$ upon changes in systemic oxygenation in extubated cardiac surgery patients. As a secondary objective, we analyzed whether the devices differ in their ability to detect a critically reduced $\mathrm{SvO}_{2}$ further supporting an influence of the systemic oxygen balance on the $\mathrm{ScO}_{2}$ signal.

\section{Methods}

After approval by the local ethics committee (15-187; 12 August 2015) and obtaining written informed consent, 48 consecutive, extubated, spontaneously breathing patients were included in this prospective observational study. The patient flow is depicted in Fig. 1. Patients were eligible to be included if they were scheduled for elective cardiac surgical procedures for which hemodynamic monitoring with a pulmonary artery catheter was established according to institutional standards. All patients were examined postoperatively after cardiac surgery between 9 February

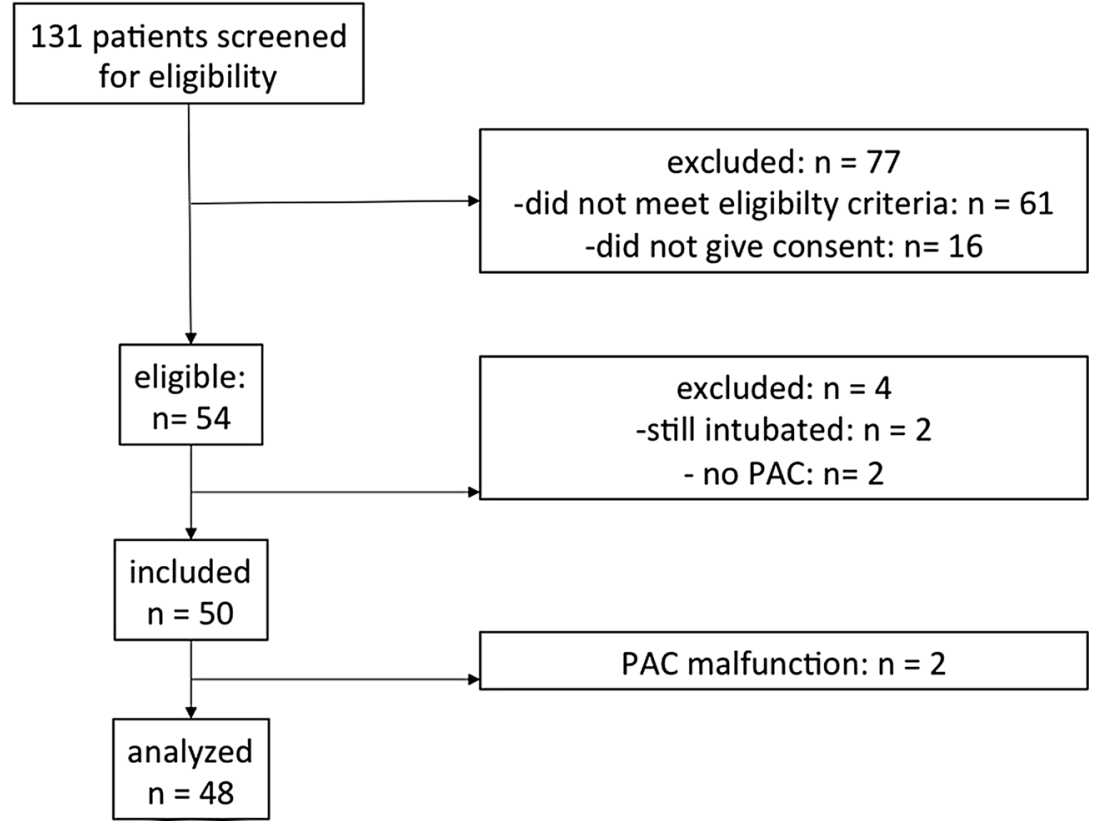

Initial measurement with

Foresight Elite :

$n=15$
Initial measurement with

INVOS :

$n=33$

Fig. 1 Consort chart depicting the patient flow in the study 
and 25 July 2016 at the Department of Cardiac and Thoracic Vascular Surgery of the University of Luebeck, Germany.

\section{Perioperative management}

All patients were instrumented with a pulmonary artery catheter connected to a Vigilance II monitor (Edwards Lifesciences; Irvine, CA, USA) for continuous monitoring of $\mathrm{SvO}_{2}$ and cardiac output (CCombo).

Intraoperative management was performed according to institutional standards that aimed for a heart rate of 60-90 beats. $\min ^{-1}$, a mean arterial pressure (MAP) of 70-100 $\mathrm{mmHg}$, a central venous pressure between $8-12 \mathrm{mmHg}$, a cardiac index $>2 \mathrm{~L} \cdot \mathrm{min}^{-1} \cdot \mathrm{m}^{-2}$, and an $\mathrm{SvO}_{2}>65 \%$. Fluid management consisted of a continuous infusion of 2 $\mathrm{mL} \cdot \mathrm{kg}^{-1} \cdot \mathrm{hr}^{-1}$ of a balanced crystalloid solution. Albumin $5 \%$ and $20 \%$ was also used for volume replacement. A low MAP or cardiac output, despite normovolemia, was treated by vasopressors (e.g., norepinephrine, vasopressin) and inotropes (e.g., levosimendan, milrinone, and dobutamine), respectively.

After surgery, all patients were transferred to the intensive care unit (ICU) while still being mechanically ventilated. They were subsequently extubated when the extremities were warm, body temperature was $\geq 36^{\circ} \mathrm{C}$, they were hemodynamically stable on only moderate pharmacologic support, were well oxygenated $\left(\mathrm{SaO}_{2}>\right.$ $95 \%$ with fraction of inspired oxygen $\leq 50 \%$ and positive end-expiratory pressure $<10 \mathrm{cmH}_{2} \mathrm{O}$ ), and had no overt signs of acute neurologic dysfunction.
Study measurements

All study endpoint measurements were made after extubation when the patients were breathing spontaneously and were hemodynamically stable without any acute need for fluid replacement and/or changes in vasoactive therapy. To prepare for the experiments, the correct position of the pulmonary artery catheter was verified by chest x-ray and pulmonary artery pressure curve analysis.

Cerebral oxygen saturation was determined with the INVOS 5100-C and the ForeSight Elite cerebral oximeters. Due to institutional standards, all patients undergoing cardiac surgery are monitored intraoperatively bihemispherically with the INVOS system and are transferred to the ICU with the sensors in place. In cases where the NIRS sensors had been removed from study patients after ICU admission but before the measurements or were no longer adequately fixed to the skin, we started the series of measurements with the ForeSight device instead. In every other case, measurements were started using the INVOS.

The experimental protocol is outlined in Fig. 2. In a first step, we increased oxygen supplementation by face mask to $10 \mathrm{~L} \cdot \mathrm{min}^{-1}$ and, after a $15-\mathrm{min}$ stabilization period, measured the arterial blood gases as well as $\mathrm{SvO}_{2}$ for in vivo calibration of the fibreoptic pulmonary artery catheter. Blood gas analysis was performed on a standard blood gas analyzer (GEM 4000 Premier; Instrumentation Laboratory; Bedford, MA, USA). Thereafter, $\mathrm{ScO}_{2}, \mathrm{SvO}_{2}$, and the hemodynamics were documented from the patient

Fig. 2 Experimental protocol
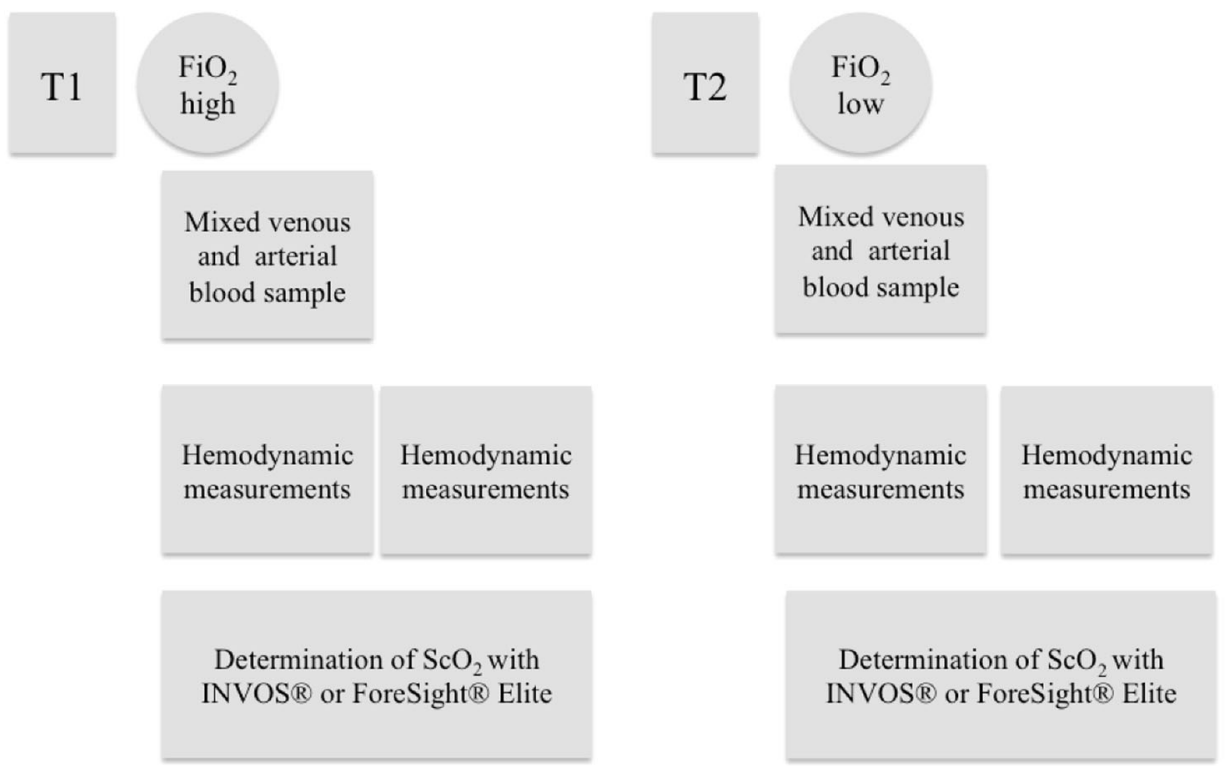

$15 \mathrm{~min}$

$15 \mathrm{~min}$

$15 \min$

$15 \mathrm{~min}$ 
monitors. In a next step, we changed the NIRS optodes from INVOS to ForeSight, or vice versa, and after another 15 min again documented $\mathrm{ScO}_{2}, \mathrm{SvO}_{2}$, and the hemodynamics. To adjust for possible changes of the circulatory status within these measurement periods (when changing the optodes), the $\mathrm{SvO}_{2}$ values displayed by the Vigilance II monitor were used for statistical analyses, while the respective blood gas analyses were used to check for plausibility of the displayed values as well as for calculation of oxygen delivery.

As a second step of the experiment, oxygen supplementation was stopped and patients were allowed to breathe room air. If $\mathrm{SaO}_{2}$ decreased to $<90 \%$, oxygen supplementation was resumed with 1 or $2 \mathrm{~L} \mathrm{O}_{2} \cdot \min ^{-1}$ by face mask to maintain an $\mathrm{SaO}_{2} \geq 90 \%$. After another 15min stabilization period with room air (or low inspiratory oxygen supplementation), the $\mathrm{ScO}_{2}, \mathrm{SvO}_{2}$, and hemodynamics were recorded, and arterial and mixed venous samples for blood gas analysis were drawn. Depending on the sequence, NIRS sensors were again changed from INVOS to ForeSight, or vice versa, and measurements were repeated after another 15-min equilibration period.

\section{Statistical analyses}

The sample size was determined by convenience according to previous observations on the differential relationship between $\mathrm{ScO}_{2}$ and $\mathrm{SvO}_{2}$ upon variations of arterial blood pressure. ${ }^{12}$ The distribution of variables was tested for normality using the Lilliefors test. Continuous variables are presented as mean (standard deviation [SD]) or median [interquartile range (IQR)], as appropriate. Descriptive analyses for normally distributed data were performed by paired Student's $t$ test; non-normally distributed data were analyzed with Wilcoxon's test. For the construction of the confidence interval for the median difference, the assumption of symmetric distribution was checked and was found not to be violated.

Correlation analyses were performed for the individual data sets (i.e., for each measurement during high or low oxygen supplementation) as well as for the combined data for each device. Since most of the oxygenation data were normally distributed (Table, available as electronic supplementary material), correlation analyses were performed with Pearson's correlation coefficient. Differences between correlations were determined by Fisher's $\mathrm{Z}$ transformation using the cocor framework for the $\mathrm{R}$ statistical language. ${ }^{20}$ Differences in correlations were calculated according to $\mathrm{Zou}^{21}$ using equations 3 to 7 from the respective publication. The Bonferroni multiple comparison adjustment was used for all comparisons (adjustment for four comparisons)
Receiver-operating curve (ROC) analyses (De Long method) were performed to determine the predictive capacity of $\mathrm{ScO}_{2}$ to determine an $\mathrm{SvO}_{2}$ below $60 \%$ or $50 \%$ for each device.

Statistical significance was considered at $P<0.05$. Comparisons between oxygenation and hemodynamic variables and correlations were adjusted for multiple testing by the Bonferroni method with the multiplicand 4 . Statistical analyses were performed with MedCalc 17.6 for Windows (MedCalc software, Ostend, Belgium) and $\mathrm{R}$ version 3.2.2 (Development Core Team; $2015 \mathrm{R}$ : a language and environment for statistical computing. $\mathrm{R}$ Foundation for Statistical Computing, Vienna, Austria. ISBN 3-900051-07-0, http://www.R-project.org/).

\section{Results}

Forty-eight patients (12 females and 36 males) were analyzed and the mean (SD) age was 68.7 (10.6) yr. Patient characteristics, surgical variables, and concomitant vasoactive and inotropic medication use are presented in Table 1.

\section{Descriptive analyses}

Arterial oxygen saturation $\left(\mathrm{SaO}_{2}\right)$ and oxygen delivery were significantly higher during high than low oxygen supplementation (Table 2). Upon variation of the oxygen levels, concordant changes in $\mathrm{SvO}_{2}$ and $\mathrm{ScO}_{2}$ (with both oximeters) were observed. Systemic hemodynamics revealed a small but significant increase in mean pulmonary arterial pressure from high to low oxygenation. A minor decrease in MAP was only observed for the INVOS comparison during reduction of oxygen supplementation (Table 2).

The median [IQR] bi-hemispherical average $\left(\mathrm{ScO}_{2 \text { avg }}\right)$ levels during high-level oxygen supplementation were not different between the INVOS or the ForeSight oximeter $\left(\mathrm{ScO}_{\text {2avg: }}\right.$ : 65.5 [62.4-69.5] \% vs 67.0 [65.0-70.1] \%; median difference, $-1.5 \%$; Bonferroni-adjusted $95 \%$ confidence interval $[\mathrm{CI}],-4.5 \%$ to $1.0 \% ; P=0.08$ ), nor were the mean (SD) minimal $\mathrm{ScO}_{2}\left(\mathrm{ScO}_{2 \mathrm{~min}}\right)$ levels $\left[\mathrm{ScO}_{2 \min }: 63.1\right.$ (8.6) \% vs 65.8 (4.7) \%, respectively; mean difference, $-2.6 \%$; Bonferroni-adjusted $95 \% \mathrm{CI}$, $-6.4 \%$ to $1.1 \% ; P=0.07]$.

During low oxygen levels, the respective INVOS readings for the $\mathrm{ScO}_{2 \text { avg }}$ were significantly lower than the ForeSight measurements (59.3 [56.4-64.0] \% vs 63.0 [61.0$66.0] \%$, respectively; median difference, $-3.5 \%$; Bonferroni-adjusted $95 \% \mathrm{CI},-6.8 \%$ to $-1.0 \% ; P<$ $0.001)$ as were the $\mathrm{ScO}_{2 \min }$ measures [56.7 (8.9) \% vs 61.3 (4.4) \%, respectively; mean difference, $-4.6 \%$; 
Bonferroni-adjusted $95 \% \mathrm{CI},-8.4 \%$ to $-0.79 \% ; P=$ 0.003] (Table 2). No significant differences in arterial oxygen saturation or hemodynamics were observed within the high or low oxygen saturation periods during the measurement periods with the different oximeters (Table 2).

\section{Primary endpoint}

Correlation analyses during the individual measurement periods of low and high oxygen delivery revealed significant correlations [ $\mathrm{r}$ (Bonferroni-adjusted 95\% CI) = $0.41(0.15$ to 0.62$)$ to 0.60 (0.39 to 0.76$)$ ] between $\mathrm{ScO}_{2}$ determined by INVOS and $\mathrm{SvO}_{2}$ but no correlation (r [Bonferroni-adjusted $95 \% \mathrm{CI}$ ] $=0.06[-0.20$ to 0.32 ] to 0.13 [-0.16 to 0.40$]$ ) between $\mathrm{ScO}_{2}$ determined by ForeSight Elite and $\mathrm{SvO}_{2}$ (Table 3). Analysis of the combined high and low oxygen supplementation data sets revealed a significant difference in the correlation between $\mathrm{ScO}_{2 \text { min }}$ and $\mathrm{SvO}_{2}$ determined with the INVOS and the ForeSight Elite oximeters (0.59, INVOS vs 0.28, ForeSight; correlation difference, $0.31 ; 95 \% \mathrm{CI}, 0.08$ to $0.54 ; P=$ 0.008) (Table 3, Fig. 3).

\section{Secondary endpoint}

The ROC analyses revealed an area under the curve (AUC) of 0.76 (95\% CI, 0.66 to $0.84 ; P<0.001)$ and $0.83(95 \%$ CI, 0.74 to $0.9 ; P=0.005$ ) for detecting an $\mathrm{SvO}_{2}$ below $60 \%$ and $50 \%$ by $\mathrm{ScO}_{2 \min }$ with the INVOS $5100-\mathrm{C}$ and an

Table 1 Patient demographic and perioperative characteristics

\begin{tabular}{lc}
\hline Age $(\mathrm{yr})$ & $68.7(10.6)$ \\
Male & $36(75 \%)$ \\
Female & $12(25 \%)$ \\
Height $(\mathrm{cm})$ & $174.6(7.7)$ \\
Weight $\left(\mathrm{kg} \cdot \mathrm{m}^{-2}\right)$ & $85.3(19.9)$ \\
CABG & $20(41.7 \%)$ \\
Valve surgery & $14(29.2 \%)$ \\
Combined CABG and valve surgery & $6(12.5 \%)$ \\
Other cardiac surgical procedure & $8(16.7 \%)$ \\
IABP & $6(12.5 \%)$ \\
Treatment with norepinephrine & $15(31.3 \%)$ \\
Norepinephrine dose $\left(\mathrm{mg}^{-1} \mathrm{hr}^{-1}\right)$ & $0.19(0.11)$ \\
Treatment with vasopressin & $5(10.4 \%)$ \\
Vasopressin dose $\left(\mathrm{U}^{-1} \mathrm{hr}^{-1}\right)$ & $1(0.61)$ \\
Treatment with dobutamine & $7(14.6 \%)$ \\
Dobutamine dose $\left(\mathrm{mg}^{-1} \mathrm{hr}^{-1}\right)$ & $13.6(4.7)$ \\
Treatment with levosimendan & $12(25 \%)$ \\
\hline
\end{tabular}

Data are presented as mean (standard deviation [SD]) or percentage $(\%)$. $\mathrm{CABG}=$ coronary artery bypass grafting; IABP = intra-aortic balloon counterpulsation
AUC of 0.61 (95\% CI, 0.50 to $0.70 ; P=0.12)$ and 0.51 (95\% CI, 0.41 to $0.62 ; P=0.92$ ) with the ForeSight Elite oximeter, respectively.

\section{Discussion}

The present observational study shows that the INVOS 5100-C and ForeSight Elite cerebral oximeters react differently to variations in oxygen delivery and correlate differently with $\mathrm{SvO}_{2}$. Furthermore, the predictive capacity to determine an $\mathrm{SvO}_{2}$ in the critical range $(<50 \%$ or $60 \%)$ is not comparable between the devices. The lack of correlation in the individual measurement periods and significantly less pronounced correlation between $\mathrm{SvO}_{2}$ and $\mathrm{ScO}_{2 \text { ForeSight }}$ in comparison with $\mathrm{ScO}_{2 \text { Invos }}$ in the combined data set of the present study suggest that the ForeSight Elite oximeter is influenced to a lesser extent by changes in the systemic oxygen delivery and systemic oxygen balance than the INVOS system.

The cerebral oximeters used in this study differ with respect to the sensor technology, wavelengths, and algorithms used to calculate $\mathrm{ScO}_{2} \cdot{ }^{15}$ As there is no gold standard for calibrating cerebral oximeters, it is not surprising that these technologic differences might lead to varying absolute $\mathrm{ScO}_{2}$ values within the same subject. ${ }^{18}$ Additionally, previous work in healthy volunteers has also shown that the $\mathrm{ScO}_{2}$ signal is variably influenced by the perfusion of extracranial tissue and that the INVOS oximeter readings are influenced to a greater degree by "extracranial contamination" than the ForeSight Elite device. 16,17 Thus, one may speculate that this confounding variable may, at least in part, explain that the INVOS $5100 \mathrm{C}$ signal is affected to a greater extent, and the ForeSight Elite signal to a lesser extent, by variations in the systemic oxygen balance. This, however, may have relevant clinical implications if both devices are used interchangeably in clinical studies ${ }^{22}$ and according to specific algorithms that have primarily been developed for one specific device. ${ }^{23}$

Without doubt, the $\mathrm{ScO}_{2}$ readings derived from both devices reflect cerebral blood flow and cerebral oxygen balance. $^{1,2,24-26}$ Nevertheless, the results from various studies support the notion that INVOS-derived $\mathrm{ScO}_{2}$ is also reflective of cardiopulmonary function $^{14}$ and the systemic ratio between oxygen delivery and demand, ${ }^{10,11}$ while only sparse data on such interactions have been reported for the ForeSight Elite monitor. ${ }^{12}$ Interestingly, and with only a few exceptions, ${ }^{7}$ most of the evidence on the usefulness of cerebral oximetry has been gathered using the INVOS system. ${ }^{1-6,8,19}$ Based on our findings, one may thus speculate that the beneficial "systemic" effects observed in studies employing the INVOS oximeter (i.e., 
Table 2 Hemodynamics and oxygenation indices in spontaneously breathing patients after cardiac surgery during high and low inspiratory oxygen concentration

\begin{tabular}{|c|c|c|c|c|}
\hline & Inspiratory oxygen & INVOS 5100-C & ForeSight Elite & $P$ value \\
\hline CI & High & $2.9(0.5)$ & $2.9(0.5)$ & 0.46 \\
\hline$\left[\mathrm{L} \cdot \mathrm{min}^{-1} \cdot \mathrm{m}^{-2}\right]$ & Low & $2.8(0.5)$ & $2.8(0.5)$ & 0.68 \\
\hline$P$ value & & 0.11 & 0.07 & \\
\hline MAP & High & $79.9(9.7)$ & $79.8(9.3)$ & 0.67 \\
\hline$[\mathrm{mmHg}]$ & Low & $76.9(10.3) *$ & $76.7(9.3)$ & 0.76 \\
\hline$P$ value & & 0.004 & 0.02 & \\
\hline CVP & High & $14.0[11.5-18.0]$ & $14.0[11.0-18.0]$ & 0.82 \\
\hline$[\mathrm{mmHg}]$ & Low & $15.0[11.0-18.0]$ & $15.0[11.0-18.0]$ & 0.38 \\
\hline$P$ value & & 0.79 & 0.32 & \\
\hline PAPM & High & $26.8[24.1-29.4]$ & $25.0[22.3-30.8]$ & 0.33 \\
\hline$[\mathrm{mmHg}]$ & Low & $27.0[24.0-32.0] *$ & $27.0[23.0-33.3] *$ & 0.17 \\
\hline$P$ value & & 0.01 & 0.001 & \\
\hline $\mathrm{SaO}_{2}$ & High & 98.8 [98.1-99.4] & $98.8[98.1-99.4]$ & - \\
\hline [\%] & Low & $93.8[92.0-96.6] *$ & $93.8[92.0-96.6] *$ & - \\
\hline$P$ value & & $<0.001$ & $<0.001$ & \\
\hline $\mathrm{ScO}_{2 \min }$ & High & $63.1(8.6)$ & $65.8(4.7)$ & 0.07 \\
\hline$[\%]$ & Low & $56.7(8.9) *$ & $61.3(4.4) * \#$ & 0.003 \\
\hline$P$ value & & $<0.001$ & $<0.001$ & \\
\hline $\mathrm{ScO}_{2 \text { avg }}$ & High & 65.5 [62.4-69.5] & $67.0[65.0-70.1]$ & 0.08 \\
\hline$[\%]$ & Low & $59.3[56.4-64.0] *$ & $63.0[61.0-66.0] * \#$ & $<0.001$ \\
\hline$P$ value & & $<0.001$ & $<0.001$ & \\
\hline $\mathrm{SvO}_{2}$ & High & $68.6(7.1)$ & $68.7(7.1)$ & 0.94 \\
\hline [\%] & Low & $60.1(9.4) *$ & $60.1(9.1) *$ & 0.47 \\
\hline$P$ value & & $<0.001$ & $<0.001$ & \\
\hline $\mathrm{Hb}$ & High & $9.3[8.7-9.8]$ & $9.3[8.7-9.8]$ & - \\
\hline$\left[\mathrm{mg} \cdot \mathrm{dl}^{-1}\right]$ & Low & 9.3 [8.6-10.05] & 9.3 [8.6-10.05] & - \\
\hline$P$ value & & 0.74 & 0.74 & \\
\hline $\mathrm{DO}_{2}$ & High & 380.8 (73.6) & 374.1 (70.6) & 0.46 \\
\hline$\left[\mathrm{mL} \cdot \mathrm{min}^{-1}\right]$ & Low & $350.1(77.8) *$ & $344.5(71.9) *$ & 0.68 \\
\hline$P$ value & & $<0.001$ & $<0.001$ & \\
\hline
\end{tabular}

Data are presented as mean (standard deviation [SD]) for normally or median [interquartile range (IQR)] for not normally distributed variables. $\mathrm{CI}=$ cardiac index $\mathrm{CVP}=$ central venous pressure; $\mathrm{DO}_{2}=$ oxygen delivery; $\mathrm{Hb}=$ hemoglobin; $\mathrm{MAP}=$ mean arterial pressure; $\mathrm{PAPM}=$ mean pulmonary artery pressure; $\mathrm{SaO}_{2}$ and $\mathrm{SvO}=$ arterial and mixed venous oxygen saturation; $\mathrm{ScO}_{2 \text { avg }}$ and $\mathrm{ScO}_{2 \text { min }}=$ average bi-hemispherical and minimal cerebral oxygen saturation determined by near-infrared spectroscopy with either INVOS 5100-C or ForeSight Elite. *Significant difference $(P<0.0125$; after Bonferroni adjustment) between T1 (high oxygenation) and T2 (low oxygenation). \#Significant difference $(P<$ 0.0125; after Bonferroni adjustment) between the INVOS and the ForeSight Elite measurements

reductions in overall complications $)^{6}$ may, at least in part, also be attributable to a better preservation of the systemic oxygen balance.

In contrast, the lack of association between the ForeSight Elite measurements and the systemic oxygen balance suggests that the $\mathrm{ScO}_{2}$ readings from this device are (at least partially) independent from the systemic oxygen balance. Indeed, our data do not allow any firm conclusions about this issue. Furthermore, if this can be explained by the fact that the measurements of this oximeter are indeed more reflective of the cerebral oxygenation than those derived from the INVOS monitor, then this question needs to be addressed employing a different experimental protocol and invasive measurements that cannot be integrated into routine clinical practice and an observational study design like this.

Nevertheless, our data clearly question if the current algorithms used to optimize (or maintain) $\mathrm{ScO}_{2}$ in clinical practice, that have been developed for the INVOS monitor and that-among a few brain specific variablespredominantly focus on the optimization of systemic hemodynamics, ${ }^{23}$ can be effectively transferred if using the ForeSight Elite oximeter. Moreover, one may also speculate that the "systemic" effects of interventions 
Table 3 Correlation coefficients between bi-hemispherical mean and minimal cerebral oxygen saturation measurements derived from INVOS 5100-C or Foresight Elite and mixed venous oxygen

\begin{tabular}{|c|c|c|c|c|}
\hline & & INVOS & Foresight & $\begin{array}{l}95 \% \mathrm{CI} \text { for differences } \\
P \text { value }\end{array}$ \\
\hline & $\begin{array}{l}\mathrm{F}_{1} \mathrm{O}_{2} \text { high } \\
(n=48)\end{array}$ & $\begin{array}{l}0.42 \\
(0.16 \text { to } 0.63) ; \\
P=0.003\end{array}$ & $\begin{array}{l}0.10 \\
(-0.20 \text { to } 0.36) \\
P=0.56\end{array}$ & $\begin{array}{l}(-0.06 \text { to } 0.68) \\
P=0.10\end{array}$ \\
\hline \multirow[t]{3}{*}{$\mathrm{SvO}_{2}$ vs $\mathrm{ScO}_{2 \min }$} & $\begin{array}{l}\mathrm{F}_{1} \mathrm{O}_{2} \text { low } \\
(n=48)\end{array}$ & $\begin{array}{l}0.60 \\
(0.39 \text { to } 0.76) \\
P<0.0001\end{array}$ & $\begin{array}{l}0.10 \\
(-0.19 \text { to } 0.37) \\
P=0.50\end{array}$ & $\begin{array}{l}(0.15 \text { to } 0.83) \\
P=0.005 \\
\#\end{array}$ \\
\hline & $\begin{array}{l}\mathrm{F}_{1} \mathrm{O}_{2} \text { high }+ \text { low } \\
(n=96)\end{array}$ & $\begin{array}{l}0.59 \\
(0.43 \text { to } 0.70)\end{array}$ & $\begin{array}{l}0.28 \\
(0.09 \text { to } 0.46)\end{array}$ & $\begin{array}{l}(0.08 \text { to } 0.54) \\
P=0.008\end{array}$ \\
\hline & $\begin{array}{l}\mathrm{F}_{1} \mathrm{O}_{2} \text { high } \\
(n=48)\end{array}$ & $\begin{array}{l}P=0.001 \\
0.41 \\
(0.15 \text { to } 0.62) \\
P=0.004\end{array}$ & $\begin{array}{l}P=0.006 \\
0.14 \\
(-0.14 \text { to } 0.41) \\
P=0.31\end{array}$ & $\begin{array}{l}\# \\
(-0.04 \text { to } 0.70) \\
P=0.07\end{array}$ \\
\hline \multirow[t]{2}{*}{$\mathrm{SvO}_{2}$ vs $\mathrm{ScO}_{2 \text { avg }}$} & $\begin{array}{l}\mathrm{F}_{1} \mathrm{O}_{2} \text { low } \\
(n=48)\end{array}$ & $\begin{array}{l}0.59 \\
(0.36 \text { to } 0.75) \\
P<0.001\end{array}$ & $\begin{array}{l}0.13 \\
(-0.16 \text { to } 0.40) \\
P=0.37\end{array}$ & $\begin{array}{l}(0.11 \text { to } 0.79) \\
P=0.01 \\
\#\end{array}$ \\
\hline & $\begin{array}{l}\mathrm{F}_{1} \mathrm{O}_{2} \text { high }+ \text { low } \\
(n=96)\end{array}$ & $\begin{array}{l}0.60 \\
(0.45 \text { to } 0.71) \\
P<0.001\end{array}$ & $\begin{array}{l}0.32 \\
(0.13 \text { to } 0.49) \\
P=0.001\end{array}$ & $\begin{array}{l}(0.06 \text { to } 0.50) \\
P=0.02\end{array}$ \\
\hline
\end{tabular}

Data are the correlation coefficients (Bonferroni-adjusted 95\% confidence intervals $[\mathrm{CI}]$ ). $\mathrm{F}_{1} \mathrm{O}_{2}=$ fraction of inspired oxygen; ScO $\mathrm{O}_{2 \text { avg }}$ and $\mathrm{ScO}_{2 \min }=$ bi-hemispherical mean and minimal cerebral oxygen saturation; $\mathrm{SvO}_{2}=$ mixed venous oxygen saturation. \#Significant difference $(P<$ 0.0125; after Bonferroni adjustment) between the INVOS and ForeSight Elite measurements

on maintaining cerebral oxygen saturation determined with the ForeSight Elite oximeter might differ from those obtained when using the INVOS system. Consequently, it remains to be determined if the strategies to improve $\mathrm{ScO}_{2}$ that have been shown to be effective for one oximeter ${ }^{6,8}$ will also be effective if other oximeters are used and which specific oximeter will be most useful for a given endpoint. In line with this assumption, the first multicentre study aiming to test the feasibility of a well-accepted algorithm developed for the INVOS system for perioperative optimization of cerebral oxygen saturation in cardiac surgical patients did not show outcome differences despite a reduction in cerebral desaturation load when using multiple cerebral oximeters from different manufacturers. $^{22}$

It is at least debatable if the well-described associations between decreased $\mathrm{ScO}_{2 \mathrm{INVOS}}$ and adverse outcomes ${ }^{1-5}$ may also be observed for $\mathrm{ScO}_{2 \text { ForeSight }}$ during conditions in which a decrease in cerebral oxygenation is primarily driven by variations in systemic hemodynamics and poor cardiopulmonary function (i.e., outside the setting of cardiopulmonary bypass). In this regard, it is of note that a recent study performed with the ForeSight Elite device failed to show an association between cerebral desaturation and postoperative complications, while only NIRS-derived somatic tissue oxygenation was predictive of postoperative complications and hospital length of stay. ${ }^{9}$ These findings contrast with several other observations in the noncardiac surgery field (obtained with the INVOS), ${ }^{5,27}$ but may be easily explained by the findings of the present study and the less pronounced reactivity of the ForeSight system to changes in systemic hemodynamics.

This study has several limitations. First, and in line with other studies in this field, ${ }^{12}$ we did not perform a formal power analysis to calculate the sample size and conveniently adjusted the patient size to that of a recent publication that had shown differences between the INVOS and the ForeSight Elite monitor. Nevertheless, retrospective analyses show that the chosen sample size would have been sufficient to detect a significant difference in correlation coefficients from 0.77 (previously observed during a comparable experimental setup) to 0.5 or less, suggesting that this study was sufficiently powered to detect clinically relevant differences between the devices. Second, we did not randomize the sequence in which the cerebral oximetry optodes were used and also refrained from varying the oxygenation periods. Though this could have theoretically been done, but as the inclusion of a 


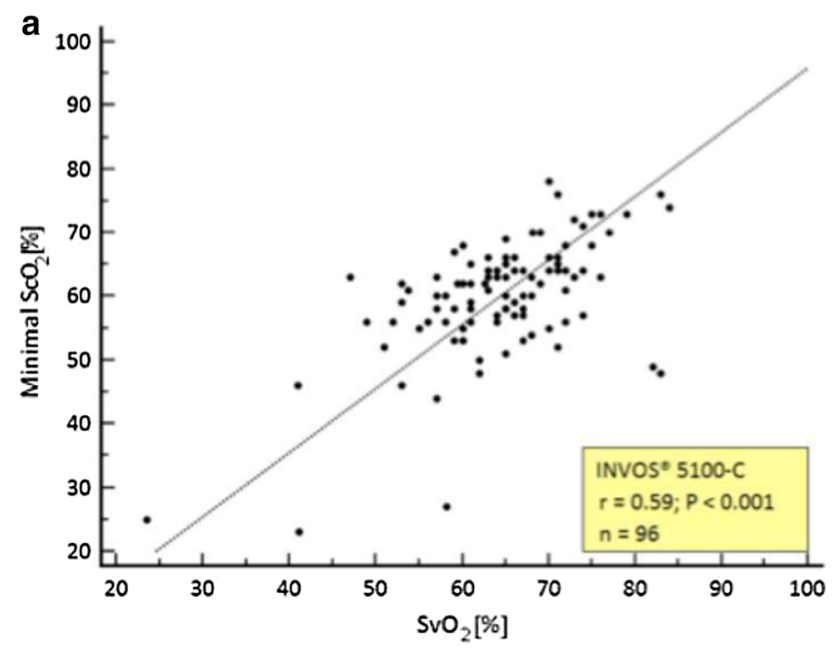

Fig. 3 Correlation analyses for the bi-hemispherical minimal cerebral oxygen saturation $\left(\mathrm{ScO}_{2}\right)$ measurements derived from INVOS 5100-C (a) and Foresight Elite (b) and mixed venous

formal randomization process would have changed the study from an observational trial to a formal medical device comparison study, it would have mandated a different approval process and expensive insurance fees. To minimize the bias that this lack of randomization may have introduced, we started with the INVOS optodes routinely used for postoperative monitoring in the ICU only in cases where these optodes were still perfectly attached to the patient's forehead. In all other cases-i.e., if a patient was sweating or the optodes had been unintentionally removed - we started with Foresight Elite. Similarly, since a formal randomization of the oxygen supplementation periods was also not possible, we used 15 min of equilibration with the respective sensors and between oxygen supplementations to reduce this possible bias. Nonetheless, this lack of formal randomization clearly tempers the conclusions that can be drawn from this study and mandates replication with a more formal experimental setup.

An additional limitation relates to the correlations between $\mathrm{SvO}_{2}$ and $\mathrm{ScO}_{2 \mathrm{INVOS}}$ observed in this study that were slightly weaker than observed in previous trials by our group. ${ }^{10,11}$ Whether this was attributed to the lower baseline $\mathrm{ScO}_{2}$ levels and/or hemoglobin concentrations in the present study or differences in the vasoactive medications used remains speculative. A final limitation is that despite the patients being clinically stable during the measurements (requiring that no adjustments in vasoactive and inotropic therapy were made), small $(2 \mathrm{mmHg})$ but significant changes in mean pulmonary artery pressure were observed comparing the the high and low oxygenation periods. Additionally, the MAP was slightly

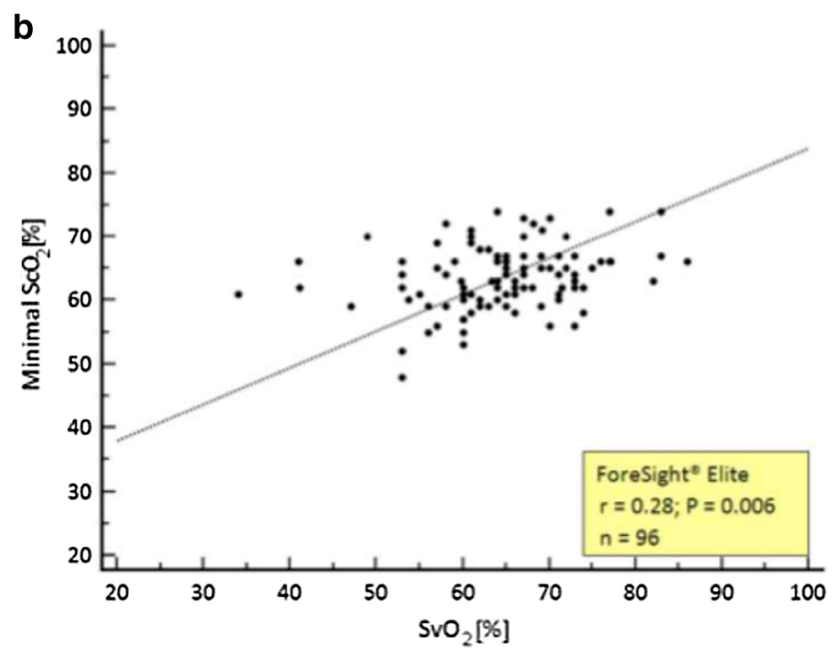

oxygen saturation $\left(\mathrm{SvO}_{2}\right)$ in patients after cardiac surgery for the combined periods of high and low oxygen supplementation. The correlation coefficients were significantly different $(P=0.008)$

(3 $\mathrm{mmHg}$ ) lower during the INVOS measurements. Nevertheless, the changes observed were not generally clinically significant and thus most likely did not interfere with the findings of the present study.

In conclusion, the present study suggests that two clinically established cerebral oximeters react differently to variations in systemic oxygen delivery and differ in their relationship with mixed venous oxygen saturation as well as their ability to detect a critically reduced $\mathrm{SvO}_{2}$. Although these findings need to be independently replicated in a more standardized experimental setup, they raise doubt about whether the respective devices should be used interchangeably following algorithms established for only one of these devices. Furthermore, pending a universally accepted standard for calibration of cerebral oximeters and clinical evidence that the therapeutic decisions and concepts based on the $\mathrm{ScO}_{2}$ measurements of devices manufactured according to such a standard have a comparable impact on outcomes, these results suggest caution in transferring results obtained with oximeters from different manufacturers. They also suggest that specific cut-off values for cerebral desaturation, as well as optimization interventions, need to be developed for each distinct cerebral oximeter in clinical use.

Acknowledgement We thank CAS Medical Systems, Inc., Branford, Connecticut, USA, for providing the Foresight Elite Oximeter at no cost.

Conflict of interests Matthias Heringlake has received honoraria and travel compensation for lectures and advisory board activities from Covidien/Medtronic. 
Editorial responsibility This submission was handled by Dr. Hilary P. Grocott, Editor-in-Chief, Canadian Journal of Anesthesia.

Author contributions Christian Schmidt and Matthias Heringlake designed the study, performed measurements, prepared the raw data for analyses, performed the statistical analyses, and drafted the manuscript. Patrick Kellner, Astrid Ellen Berggreen, Holger Maurer, Sebastian Brandt, Bence Bucsky, and Michael Petersen performed the measurements and critically reviewed the manuscript for important intellectual content. Efstratios I. Charitos provided critical revisions and additional statistical analyses during the review process. All authors approved the final version of this manuscript.

Funding The study was funded by institutional resources of the Department of Anesthesiology and Intensive Care Medicine, University of Lübeck, Lübeck, Germany.

\section{References}

1. Moerman A, Wouters P. Near-infrared spectroscopy (NIRS) monitoring in contemporary anesthesia and critical care. Acta Anaesthesiol Belg 2010; 61: 185-94.

2. Murkin JM, Arango M. Near-infrared spectroscopy as an index of brain and tissue oxygenation. Br J Anaesth 2009; 103(Supplement 1): i3-13.

3. Slater JP, Guarino T, Stack J, et al. Cerebral oxygen desaturation predicts cognitive decline and longer hospital stay after cardiac surgery. Ann Thorac Surg 2009; 87: 36-44.

4. de Tournay-Jetté E, Dupuis G, Bherer L, Deschamps A, Cartier $R$, Denault $A$. The relationship between cerebral oxygen saturation changes and postoperative cognitive dysfunction in elderly patients after coronary artery bypass graft surgery. J Cardiothorac Vasc Anesth 2011; 25: 95-104.

5. Casati A, Fanelli G, Pietropaoli P, et al. Monitoring cerebral oxygen saturation in elderly patients undergoing general abdominal surgery: a prospective cohort study. Eur J Anaesthesiol 2007; 24: 59-65.

6. Murkin JM, Adams SJ, Novick RJ, et al. Monitoring brain oxygen saturation during coronary bypass surgery: a randomized. prospective study. Anesth Analg 2007; 104: 51-8.

7. Mohandas BS, Jagadeesh AM, Vikram SB. Impact of monitoring cerebral oxygen saturation on the outcome of patients undergoing open heart surgery. Ann Card Anaesth 2013; 16: 102-6.

8. Colak Z, Borojevic M, Bogovic A, Ivancan V, Biocina B, MajericKogler $V$. Influence of intraoperative cerebral oximetry monitoring on neurocognitive function after coronary artery bypass surgery: a randomized. prospective study. Eur J Cardiothorac Surg 2015; 47: 447-54.

9. Meng L, Xiao J, Gudelunas $K, Y u Z$, Zhong Z, Hu X. Association of intraoperative cerebral and muscular tissue oxygen saturation with postoperative complications and length of hospital stay after major spine surgery: an observational study. Br J Anaesth 2017; 118: 551-62.

10. Paarmann $H$, Heringlake $M$, Heinze $H$, et al. Non-invasive cerebral oxygenation reflects mixed venous oxygen saturation during the varying haemodynamic conditions in patients undergoing transapical transcatheter aortic valve implantation. Interact Cardiovasc Thorac Surg 2012; 3: 268-72.
11. Schön J, Heringlake $M$, Berger $K U$, Volker Groesdonk $H$, Sedemund-Adib B, Paarmann H. Relationship between mixed venous oxygen saturation and regional cerebral oxygenation in awake. spontaneously breathing cardiac surgery patients. Minerva Anestesiol 2011; 77: 952-8.

12. Moerman A, Vandenplas G, Bové T, De Wouters PF, Hert SG. Relation between mixed venous oxygen saturation and cerebral oxygen saturation measured by absolute and relative nearinfrared spectroscopy during off-pump coronary artery bypass grafting. Br J Anaesth 2013; 110: 258-65.

13. Meng L, Cannesson $M$, Alexander BS, et al. Effect of phenylephrine and ephedrine bolus treatment on cerebral oxygenation in anaesthetized patients. Br J Anaesth 2011; 107: 209-17.

14. Heringlake $M$, Garbers $C$, Käbler JH, et al. Preoperative cerebral oxygen saturation and clinical outcomes in cardiac surgery. Anesthesiology 2011; 114: 58-69.

15. Douds MT, Straub EJ, Kent AC, Bistrick CH, Sistino JJ. A systematic review of cerebral oxygenation-monitoring devices in cardiac surgery. Perfusion 2014; 29: 545-52.

16. Davie SN, Grocott HP. Impact of extracranial contamination on regional cerebral oxygen saturation: a comparison of three cerebral oximetry technologies. Anesthesiology 2012; 116: 83440.

17. Greenberg S, Murphy $G$, Shear $T$, et al. Extracranial contamination in the INVOS $5100 \mathrm{C}$ versus the FORE-SIGHT ELITE cerebral oximeter: a prospective observational crossover study in volunteers. Can J Anesth 2016; 63: 24-30.

18. Bickler PE, Feiner JR, Rollins MD. Factors affecting the performance of 5 cerebral oximeters during hypoxia in healthy volunteers. Anesth Analg 2013; 117: 813-23.

19. Zheng $F$, Sheinberg $R$, Yee MS, Ono M, Zheng Y, Hogue $C W$. Cerebral near-infrared spectroscopy monitoring and neurologic outcomes in adult cardiac surgery patients: a systematic review. Anesth Analg 2013; 116: 663-76.

20. Diedenhofen B, Musch J. cocor: A comprehensive solution for the statistical comparison of correlations. PLoS One 2015; 10: e0121945. https://doi.org/10.1371/journal.pone.0121945.

21. Zhou GY. Toward using confidence intervals to compare correlations. Psychological Methods 2007; 12: 399-413.

22. Deschamps A, Hall $R$, Grocott $H$, et al. Cerebral oximetry monitoring to maintain normal cerebral oxygen saturation during high-risk cardiac surgery: a randomized controlled feasibility trial. Anesthesiology 2016; 124: 826-36.

23. Denault A, Deschamps A, Murkin JM. A proposed algorithm for the intraoperative use of cerebral near-infrared spectroscopy. Semin Cardiothorac Vasc Anesth 2007; 11: 274-81.

24. Steppan J, Hogue CW Jr. Cerebral and tissue oximetry. Best Pract Res Clin Anaesthesiol 2014; 28: 429-39.

25. Brady K, Joshi B, Zweifel C, et al. Real-time continuous monitoring of cerebral blood flow autoregulation using nearinfrared spectroscopy in patients undergoing cardiopulmonary bypass. Stroke 2010; 41: 1951-6.

26. Fischer $G W$. Recent advances in application of cerebral oximetry in adult cardiovascular surgery. Semin Cardiothorac Vasc Anesth 2008; 12: 60-9.

27. Kim J, Shim JK, Song JW, Kim EK, Kwak YL. Postoperative cognitive dysfunction and the change of regional cerebral oxygen saturation in elderly patients undergoing spinal surgery. Anesth Analg 2016; 123: 436-44. 